\title{
NUEVOS DOCUMENTOS PARA EL ESTUDIO DE LA APOTEOSIS DE LOS HOMBRES CÉLEBRES DEL PALACIO DEL CONGRESO DE LOS DIPUTADOS
}

\author{
VIRGINIA RAMÍREZ MARTÍN ${ }^{1}$ \\ Archivo del Congreso de los Diputados
}

\begin{abstract}
Carlos Luis de Ribera recibe y acepta el encargo de pintar la bóveda del salón de sesiones del nuevo palacio del Congreso de los Diputados y, sobre su proyecto inicial, se introducen una serie de modificaciones que afectan, entre otras cosas, a la composición final de la Apoteosis de los hombres célebres. A partir de la documentación custodiada en diversos archivos, el presente artículo pretende ayudar a identificar cuándo se producen estos cambios, quién los aconseja y cómo la composición final influirá en la construcción de la identidad nacional, debido a su presencia en el centro de una de las dos cámaras de representación de la soberanía nacional.

Palabras clave: Carlos Luis de Ribera; Congreso de los Diputados; Palacio del Congreso; Real Academia de Bellas Artes de San Fernando; Real Academia de la Historia; Ministerio de Fomento; Manuel Seijas Lozano.
\end{abstract}

NEW DOCUMENTS FOR THE STUDY OF THE APOTEOSIS

DE LOS HOMBRES CÉLEBRES IN THE MADRID CONGRESO DE LOS DIPUTADOS

Carlos Luis de Ribera received and accepted the commission to paint the ceiling of the hemicycle of the new palace of the Madrid Congreso de los Diputados. A series of modifications were introduced into the original proyect designed by Ribera, which especially affected the final composition of the Apoteosis de los hombres célebres. Based on documents preserved in several archives, the present paper attempts to demonstrate when these modifications took place, who promoted them and how the end result of the composition influenced the construction of national identity, due to its presence in one of the chambers of representation of national sovereignty.

Key words: Carlos Luis de Ribera; Congreso de los Diputados; Palacio del Congreso; Real Academia de Bellas Artes de San Fernando; Real Academia de la Historia; Ministerio de Fomento; Manuel Seijas Lozano.

Cómo citar este artículo / Citation: Ramírez Martín, Virginia (2019): "Nuevos documentos para el estudio de la Apoteosis de los hombres célebres del palacio del Congreso de los Diputados". En: Archivo Español de Arte, vol. 92, núm. 365, Madrid, pp. 51-63. https://doi.org/10.3989/aearte.2019.05.

El salón de sesiones es indubitadamente el eje del emblemático Palacio de las Cortes de la carrera de San Jerónimo de Madrid. Todo en este palacio, construido ex novo sobre las ruinas del Convento del Espíritu Santo, fue concebido para dotar, por fin y tras diversas trashumancias y penurias, al parlamento de un espacio acorde a la función que allí se había de desarrollar ${ }^{2}$. El mismo arquitecto que lo programó, Narciso Pascual y Colomer, reflexiona que la construcción

1 virginia.ramirez@congreso.es / ORCID iD: http://orcid.org/0000-0002-2202-0593.

2 Para conocer en detalle los avatares de las Cortes hasta su localización definitiva vid. Pérez-Serrano. Nótese también que la alusión a la trashumancia de las Cortes no lo es en términos generales, pues desde época temprana se le buscó acomodo y sede estable en Madrid (23). 


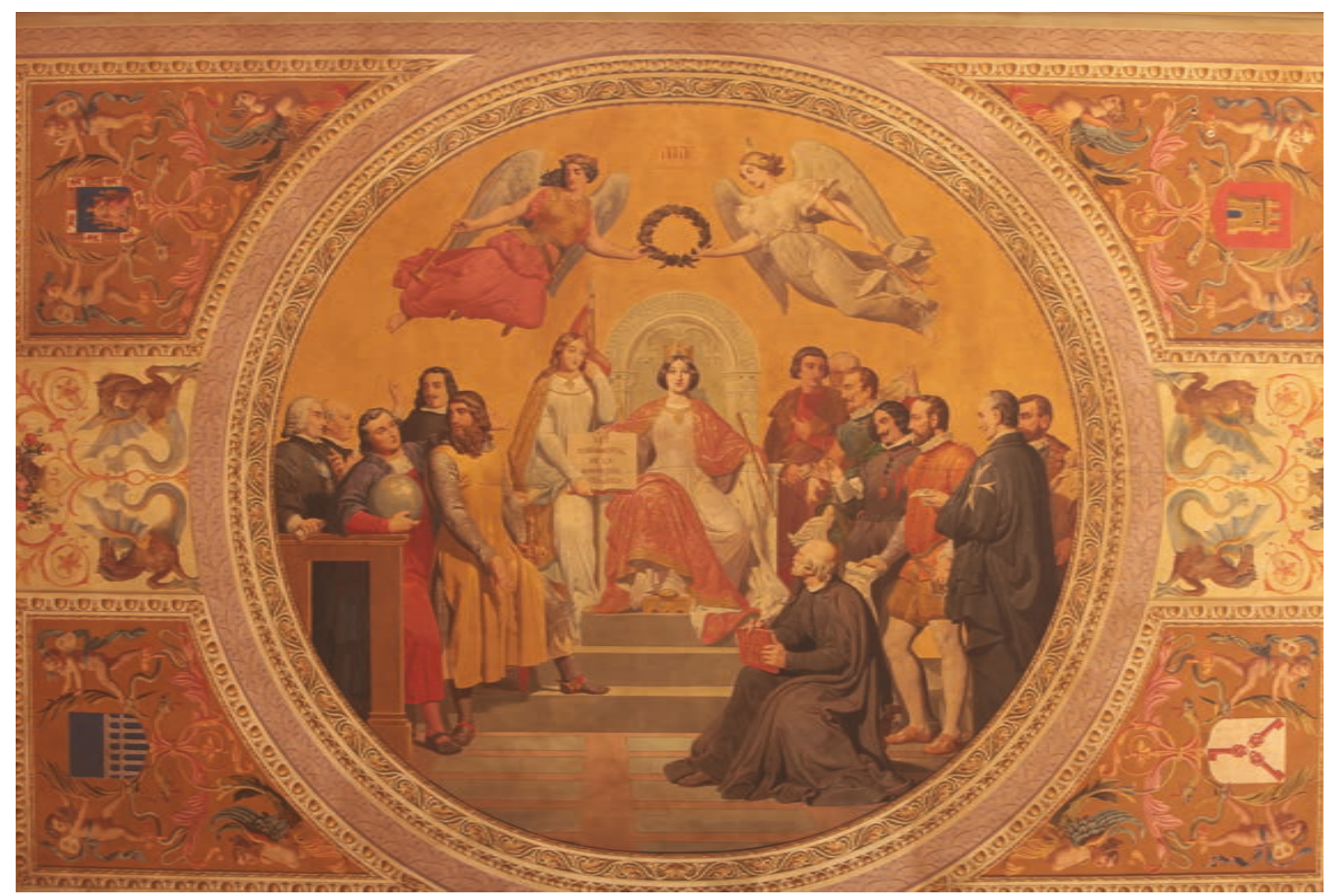

Fig. 1. Medallón de la bóveda del salón de sesiones del Congreso de los Diputados. De izquierda a derecha: Pedro Rodríguez de Campomanes; Gaspar Melchor de Jovellanos, Cristóbal Colón;

Diego de Saavedra Fajardo; El Cid; alegoría de la Constitución; España encarnada en la reina Isabel II; Juan de Mariana; Juan Luis Vives; Francisco de Salinas; Miguel de Cervantes; Diego de Silva y Velázquez; Juan de Herrera;

Lope de Vega y Alonso Berruguete.

de un edificio de estas características se considera siempre como el más fausto acontecimiento que puede ocurrir en una Nación.

El nuevo palacio es, efectivamente, un gran acontecimiento, pero, sobre todo, es un proyecto colectivo concebido y ejecutado por su arquitecto, que es auxiliado por los más destacados representantes del panorama de las Bellas Artes españolas. Los mejores de todos los oficios artísticos tienen un lugar y, como garantes de la buena ejecución y respeto al espíritu que inspira esta magna obra, dos vigías de referencia: las Reales Academias de la Historia y de las Bellas Artes de San Fernando. Asimismo, en el seno del Congreso de los Diputados se constituye una comisión al efecto para el seguimiento y la vigilancia del desarrollo de las obras: la Comisión para la Obra del Nuevo Palacio, o, simplemente, Comisión de Obras.

$\mathrm{Y}$ en el centro del corazón del parlamento, en el lugar preferente de la bóveda de su hemiciclo, se observa un gran medallón que representa las más sobresalientes figuras españolas en las diversas artes y ciencias situadas alrededor de Isabel II, que preside esta reunión de principales. Entre ellos se puede reconocer sin dificultad a Miguel de Cervantes, que nunca había presentado problemas de identificación, pues cualquier duda se solventaba con la lectura del literal "El ingenioso hidalgo Don Quijote" en las páginas que sostiene, y en un plano secundario, a Francisco Salinas, identificable por sus ojos velados y por la partitura que sujeta con su mano (fig. 1).

Sin embargo, la lectura del expediente que sobre la decoración de la bóveda del salón de sesiones conserva el Archivo del Congreso de los Diputados pone de manifiesto que ni Cervantes ni Salinas estaban inicialmente entre los personajes escogidos por el pintor Carlos Luis de Ribera, responsable de la decoración de esta bóveda, y sí todos los demás que finalmente se incluyen, aunque en varios casos eran una alternativa entre varias propuestas. Esto invitaba a pensar que alguna de las instituciones que fueron consultadas acerca de la idoneidad de este proyecto, a la 
vista de tales ausencias, propuso al pintor enmendar la falta y, en el caso de las disyuntivas, eligió la representación final.

Ya era conocido a través de la bibliografía que el proyecto de Ribera generó cierta controversia en lo relativo a la historia de la legislación que se refleja en los cuatro cuadros laterales, pero no se había reparado en la forma definitiva de la Apoteosis y sus personajes porque, como se verá después, ninguna de las academias consultadas pone objeción alguna a esta cuestión y también porque no había sido posible reconstruir documentalmente el periplo sufrido por el proyecto de Ribera hasta su aprobación definitiva. Los nuevos documentos aportados revelan la decisiva intervención del poder ejecutivo a este respecto, pues no solo se limita a dar traslado y solicitar informe a las Reales Academias, sino que apremia para que se cumplan los plazos, matiza la opinión de la Real Academia de la Historia y, finalmente, decide sobre algunos extremos.

El presente artículo pretende, pues, reconstruir a través de los expedientes conservados en distintos archivos cómo se repara la propuesta inicial del autor para incluir, entre otras modificaciones, las figuras que definitivamente habrían de estar entre los hombres ilustres llamados a ornar el cuadro principal del techo del salón de sesiones del Palacio del Congreso.

El Archivo del Congreso de los Diputados conserva los expedientes relativos a la ejecución de las obras y las actas de la comisión encargada de la vigilancia de las mismas, así como uno que lleva por título "Pintura de la bóveda del Salón de Sesiones del nuevo Palacio del Congreso de los Diputados"3. Los Archivos de las Reales Academias antecitadas, las actas de las secciones y el pleno, así como las minutas de los informes. Por su parte, el Archivo General de la Administración custodia, en un voluminoso legajo relativo a inmuebles costeados por el Estado, entre otra documentación, los informes definitivos de las academias, así como una copia de la propuesta del pintor, una modificación de la misma y la documentación del Ministerio de Comercio, Instrucción y Obras Públicas referida al palacio.

Con las noticias recogidas en todos estos expedientes y documentos se pretende analizar cómo se llegó a fijar quiénes tendrían un puesto en esta peculiar reunión de ilustres que pretendía servir de inspiración al trabajo parlamentario.

\section{El proyecto de decoración de la bóveda: la Memoria de Carlos Luis de Ribera y el expediente del Archivo del Congreso de los Diputados}

Una y otra vez, en el proyecto que Pascual y Colomer presenta para la construcción del nuevo Palacio de las Cortes y posteriormente, durante su ejecución, y en la publicación de la Memoria histórico-descriptiva a la que ya se ha hecho referencia, se alude al "decoro" 4 como brújula que dirige el desempeño de la obra. Pero la pintura de la bóveda no se concibe exclusivamente desde el decoro, sino que además pretende trascender o, como afirma el propio Ribera, "responderá á las generaciones futuras del estado en que se hallaban las artes en España á mediados del siglo $19^{a}$ que se acabó su construcción"s. Insiste después el artista en que las pinturas deben "pertenecer al género serio" e integrarse con perfecta armonía con el diseño arquitectónico del edifició.

\footnotetext{
3 ACD, Obras de Palacio, legajo 22, núm. 25.

${ }^{4}$ El decoro arquitectónico es, según recoge el Diccionario de la Real Academia Española, la parte de la arquitectura que enseña a dar a los edificios el aspecto y propiedad que les corresponde según sus destinos respectivos'. Es, pues, este concepto el que Pascual y Colomer condensa al hacer referencia en su Memoria al modo en el que concibe erigir "un monumento digno de la Representación Nacional, destinado a un objeto tan grande y tan sagrado". Por otra parte, el decoro arquitectónico se conjuga con el decoro parlamentario, casi un concepto jurídico indeterminado, que ha ido evolucionando a medida que lo hacía también la institución y el régimen político pero que se ha recogido en todos los reglamentos que han ordenado, y ordenan hoy, el funcionamiento de la cámara.

5 ACD, Obras de Palacio, legajo 22, núm. 25: "Pintura de la bóveda del Salón de Sesiones por Carlos Luis de Ribera".

${ }^{6}$ Para una descripción y análisis profundo de la decoración de la bóveda del Salón de Sesiones son indispensables los textos de Bonet-Correa y Arias del Cossío, Díez García y Navarro. En el primero se explican con detalle las influen-
} 
Su integración en la arquitectura general del palacio no solo tiene sentido porque el edificio fuese concebido como una de las más importantes obras públicas contemporáneas, sino porque es, sobre todo, emblema del nuevo tiempo político y del nuevo régimen parlamentario cimentado sobre la soberanía nacional compartida por la Corona y las Cortes. Por este motivo en torno a Pascual y Colomer se congregan los mejores de cada disciplina artística; pero el encargo que se deposita en Ribera, que es escogido por el propio arquitecto, es probablemente el más importante de todo el edificio ${ }^{7}$. El pintor gozaba ya de notable prestigio, pues era reconocido como uno de los más sólidos representantes del "academicismo purista de la corte" y, junto con Federico de Madrazo, exponente "del sector cosmopolita e intelectual de la pintura romántica madrileña"».

El programa iconográfico concebido por Ribera se articula en torno a la concepción del parlamento como "santuario de las leyes", mirando al mundo clásico y también al anglosajón, concluyendo que "la magnificencia de los edificios, no solo dan prestigio á las cosas, sino que predisponen la opinion favorable de las gentes". Convierte, pues, esta idea en el eje de la decoración que para el techo del salón de sesiones propone y, de acuerdo con el diseño arquitectónico, plantea cuatro cuadros principales que se ocupan, sucesivamente, de la época de la legislación griega, la legislación romana, la legislación goda y la que denomina "de la restauración de España”. Explica además cómo va a llevar a cabo la decoración, o adorno, de los compartimentos que están a ambos lados de la mesa de la Presidencia a través de la encarnación de las cuatro virtudes cardinales (prudencia, justicia, fortaleza y templanza), que se completa con las demás virtudes devenidas de aquellas y que se representan al pie de las fajas.

El pintor es en todo momento consciente de que su obra está llamada a ser contemplada por nacionales y extranjeros, por los hombres de su tiempo y los de las generaciones venideras; dicho en pocas palabras: su obra permanecerá. Y ello reviste el encargo de enorme solemnidad, pues pretende no solo colmar las expectativas del gusto oficial, sino superarlo y fundirse con el edificio que ocupa y la función que en él se lleva a cabo.

Explicita Ribera todos estos extremos en la Memoria que esplica el asunto que ha de representar la pintura de la bóveda del salón de sesiones del nuevo Palacio del Congreso de los Diputados, y que es presentada por él mismo a la Comisión de Obras el 17 de noviembre de 1849. En una adición de 18 de enero de 1850 describe el artista, de forma independiente y pormenorizada, la concepción del cuadro central, el medallón, justificando que "sabido es que la historia consigna los hechos célebres á las generaciones futuras; y que las artes y las ciencias forman la grandeza de las Naciones".

A continuación procede, bajo el epígrafe "Personages que en opinion del Artista deberán ponerse en el cuadro", a relacionar las figuras sobresalientes en cada ámbito. En algunos casos, como sucede con los jurisconsultos Campomanes y Jovellanos, Ribera propone la elección de uno u otro aunque, finalmente, fueron representados ambos. En lo que interesa esta vez, las letras, se escoge "Al historiador Mariana y á Lope de Vega, el fénix de los ingenios", y no existe representante alguno de la música. Acaba esta adición indicando que:

Todos estos personages, cree el artista que suscribe, que son los que más han sobresalido en las artes y en las ciencias que se trata de representar; pero si la Comisión juzga que se deben sustituir por otros más ilustres, en este caso se podran remplazar con aquellos que se designen.

\footnotetext{
cias del pintor, su estilo y la ejecución de la obra, pero además se pone en contexto el modo en el que Carlos Luis de Ribera llega a comprender la magnitud del encargo que recibe, elemento fundamental para entender la razonada y prolija justificación que desarrolla en su Memoria (269-277).

7 Jiménez-Blanco, 2011: 48.

8 Díez, 2010: 48. La buena reputación de la que gozaba Ribera, del que se tenía un "alto concepto artístico" (de Miguel, 1983: 58 y Díez García, 2010: 31), se había traducido también en reconocimiento público. Muestra de ello es que por Real Decreto de 28 de octubre de 1839 se otorga el nombramiento como Caballero de la Real Orden de Isabel la Católica a Carlos Luis de Ribera, profesor de pintura pensionado del Gobierno en aquel momento (AHN, Estado, 6.321, exp. 131). También en 1849 se convierte en pintor de cámara honorario de Isabel II.
} 
Convierte, pues, Ribera, este asunto en una cuestión sobre la que cabe que otros se pronuncien, en materia política al fin y al cabo.

Además de la Memoria y la Adición, también forma parte de este expediente otro documento relativo a la técnica escogida y que lleva por título Observaciones sobre el modo de pintar la bóveda, este último también con fecha de 18 de enero de 1850.

Al día siguiente, 19 de enero, y tras dedicar a su debate por completo y en presencia del pintor esa sesión', la Comisión de Obras se dirige al Ministro de Comercio, Instrucción y Obras Públicas para que, dada la importancia del proyecto que se pretendía emprender, fuese conocedor y otorgase su aprobación o parecer el Gobierno, oyendo para ello si así se estima a "personas ó corporaciones competentes en la materia, y se asegure de este modo el mejor acierto". Para que puedan conformar su criterio se remite copia de la memoria presentada por el autor, así como el boceto original, rogándole finalmente que resuelvan en un breve plazo, a fin de no entorpecer la ejecución de las obras.

El 25 de marzo de 1850 Carlos Luis de Ribera redacta otro documento, del que solo se conserva en este expediente una copia, pues el original se remitió al ministerio, en el que consigna varias modificaciones sobre su proyecto, y lo hace, según él mismo indica, tras conocer lo dictaminado por la Real Academia de la Historia. En lo que atañe al medallón, tan solo indica Ribera que Jovellanos puede entenderse como representante de la economía y Campomanes como jurisconsulto, encontrando de este modo justificación la presencia de ambos en la figuración final en lugar de la elección entre uno y otro que planteaba inicialmente. Finaliza este documento relacionando de nuevo los personajes que habría que representar en el quinto cuadro, esto es, el medallón.

Después de recibida la enmienda del autor, el ministro Seijas escribe de nuevo al Presidente de la Comisión de Obras para indicarle que con fecha de 29 de marzo de 1850 se ha dado una Real Orden por la que ha resultado aprobado el proyecto del pintor con las modificaciones incluidas tras emitir su parecer la Real Academia de la Historia, y que de ello ha sido enterada la Reina y el asunto cuenta ya con el parecer favorable del Consejo de Ministros. A este documento acompaña un resumen de los cinco cuadros en el que, por vez primera, figura Cervantes en la nómina de ilustres entre Mariana y Lope de Vega como representantes de las Letras. Pero aún no hay noticia alguna de Salinas.

El siguiente de los documentos del expediente es una minuta del traslado al pintor de la decisión comunicada por el ministro Seijas, que incluye tanto el acuerdo como las rectificaciones de los cuadros. Los documentos restantes aluden al abono de las cantidades comprometidas por la obra al pintor, modificaciones en el presupuesto o reanudación de los trabajos de pintura en períodos donde no se celebraron sesiones.

No termina la relación de Ribera con el Congreso de los Diputados con la finalización de los trabajos de la bóveda y la decoración al temple del gabinete de los señores ministros, sino que después, en 1860, será de nuevo requerido por la Comisión de Gobierno Interior para que lleve a cabo la pintura de los cuadros triangulares del salón de sesiones ${ }^{10}$. Fruto de todo ello, la comisión acuerda en su sesión de 30 de noviembre de ese mismo año proponer al Ministro de Estado que se conceda al pintor la Cruz de Caballero de la Orden de Carlos III, indicando en su oficio que esto se hace "teniendo en consideración el singular mérito de las obras de pintura que ha ejecuta-

9 Da noticia de ello Navascués a partir de las actas de esta comisión (2007, 98) y puede también confirmarse de primera mano en el Acta de la Sesión de la Comisión para la Obra del Nuevo Palacio (ACD, Obras de Palacio, Acta núm. 588). Se recoge que el pintor estaba presente y que se trató del proyecto, incluyendo el documento copia del contenido de la memoria y proyecto, así como del tiempo y precio de su ejecución. Asimismo, lo delicado del asunto y su importancia aconsejan que se consulte "a las personas y corporaciones competentes", y se acuerda en consecuencia dirigirse al ministro Seijas para tal fin.

${ }^{10}$ ACD, Gobierno Interior, legajo 19, núm. 24: "Expediente relativo a la ejecución de los cuadros triangulares del salón de sesiones”. Se recurrió para esta tarea, en primera instancia, a Federico de Madrazo, pero finalmente se decidió no contar con él por las incontables demoras del pintor, que se explican con detalle en el Acta de la Comisión de Gobierno Interior de 17 de diciembre de 1860 y en Jiménez-Blanco, 2011: 49-53 y Díez García, 2010: 52-53. 
do en este Palacio el profesor D. Carlos Luis de Ribera, y deseando darle una señalada prueba de lo satisfecha que ha quedado de sus trabajos". Se le concede el 15 de diciembre de $1860^{11}$.

\section{Los dictámenes de las Reales Academias}

Las Reales Academias de Nobles Artes de San Fernando y de la Historia son consultadas por el Ministro de Comercio, Instrucción y Obras Públicas a fin de recabar su parece en cuanto a la memoria propuesta por el pintor. El papel de estas corporaciones no se reduce a emitir su opinión al respecto de la decoración del salón de sesiones, sino que fueron consultadas en todas las cuestiones de calado que jalonaron la construcción del nuevo palacio, cada una dentro del ámbito de sus objetivos, y que constituye una evidencia de la función consultiva que estas vienen desempeñando a lo largo de su historia.

La primera en ser consultada fue la Real Academia de las Bellas Artes ${ }^{12}$. A ella se remitieron, precedidos por un oficio suscrito por el ministro Seijas, una copia de la Memoria y el boceto presentados por Ribera, con el ruego de que emitiese la academia su informe a la mayor brevedad posible. En el margen se anota que pasa a la Sección de Pintura el 1 de febrero, sección que dictamina el 9 del mismo, y fue elevado a la Junta General que se celebró el 17.

En este expediente obra, además del informe original de la Sección de Pintura, que firma su secretario, Pedro de Madrazo, la minuta del informe de la Real Academia dirigido al ministro con fecha de 19 de febrero de 1850 . El sentido de ambos es muy positivo y se alaba con entusiasmo la propuesta de Ribera al decir que son dignas "del mayor elogio las muchas bellezas de forma y de concepto". En lo que se refiere a la forma en la que el pintor ha escogido ejecutar su obra se aprueba en todo el procedimiento y el modo en el que se justifica su elección. La Junta reproduce literalmente en el informe algunos párrafos de la opinión de la Sección de Pintura, si bien obvia la sugerencia formulada en el seno de ésta última por Javier de Quinto ${ }^{13}$, que sugiere la conveniencia de que figure la legislación aragonesa en el cuarto cuadro.

En la última línea del informe se hace constar también que se procede a la devolución del boceto y la memoria referidos, que son remitidos por el ministro Seijas el 23 de febrero de 1850 al Director de la Real Academia de la Historia por el cauce de un documento casi idéntico al recibido por la otra corporación. Sirve este para inaugurar el expediente que sobre el asunto conserva el Archivo de la Real Academia de la Historia ${ }^{14}$.

Esta debatió el proyecto de Ribera en dos sesiones, la de 1 de marzo de 1850, y otra extraordinaria que tuvo lugar el 4 del mismo, aunque previamente había encomendado a una comisión formada por tres académicos su estudio. De ambas sesiones resultó un largo y complejo informe en cuya minuta hay multitud de tachaduras y cambios, lo que inclina a pensar que hubo cierta discusión al respecto.

Comienza indicando que la academia "se ha limitado meramente a considerar el boceto y la memoria que lo explica con relación a la parte histórica", al tiempo que elogia la parte artística de la obra, dado que "encierra mérito y no podrán menos de admirar hasta los más legos" y reconoce las limitaciones y complejidad del espacio. Pero a partir de aquí la corporación critica la

11 De Cárdenas, 1996: 27.

12 ARABASF, legajo 1-16-45: "La Academia informa de Real orden y muy favorablemente sobre el indisputable mérito del boceto que el profesor de pintura de la misma D. Carlos Luis de Rivera ha presentado del techo del salón de sesiones del nuevo palacio del Congreso de Diputados de cuya ejecución está encargado dicho Sr. Rivera".

13 Se refiere a Francisco Javier de Quinto y Cortés, conde de Quinto, que fue miembro de la Real Academia de Bellas Artes y también de la de Historia y de la Española. Fue director además del Museo Nacional de Pinturas entre 1847 y 1850 y ocupó escaño en el Congreso y el Senado.

${ }^{14}$ ARAH, Secretaría, Actas de las Sesiones Académicas, tomo 21, Reunión extraordinaria del lunes 4 de marzo de 1850 y ARAH, Archivo de Secretaría, Legajo "Informes pedidos por la Academia de 1778 a 1856", año de 1850: «Expediente relativo al boceto formado por D. Carlos Luis Rivera para la pintura de los techos del Salón del Congreso de los Diputados». 
idea del pintor en aquello que atañe a la representación escogida para los cuatro cuadros que abordan la historia de la legislación, pues despacha el medallón central haciendo exclusivamente mención a "la justa apoteosis de S. M. la Reyna D. ${ }^{a}$ Isabel 2a bajo el doble carácter de Reyna Reynante, y restauradora de las libertades públicas"15.

Juzga la academia, en su prolijo análisis de los cuatro cuadros, que la representación de la legislación española queda descompensada con respecto al espacio dedicado a la universal. En el primero y el segundo de ellos dictamina que "no ha andado en el concepto de esta comisión muy acertado olvidando al pueblo hebreo, en cuyo seno tuvo principio la más competa, más sublime y más admirada de todas las legislaciones".

Refiriéndose ya al tercero y cuarto de los cuadros, los dedicados a la historia de la legislación de España, la academia encuentra diversos vacíos y lagunas, como la ausencia de Carlomagno, las crónicas antiguas o los fueros antiguos municipales, Felipe II "legislador de ambos mundos" o Carlos III. También se alude a la ausencia de Aragón, que fue objeto de reparo por uno de los académicos de Bellas Artes, como antes se ha indicado, aunque en este caso sí que se considera relevante tal falta y se incorpora, en consecuencia, al dictamen. Sigue después insistiendo en la deficiencia del planteamiento de Ribera, excepción hecha del primer cuadro y del medallón, al señalar que "De este pequeño resumen se deduce que en el pensamiento histórico del Sr. Rivera faltan cosas esenciales y otras por no serlo sobran". Tras esta detallada exposición, concluye que:

[...] sin paralizar la obra del Congreso, antes bien aprobando el conjunto del boceto del sr. Rivera, y previniéndole proceda a su ejercicio, se le encargue que deje los cuadros en blanco; y entonces, si el Gobierno conviene en ello, la Academia con el tiempo necesario para oír a todos sus individuos y para estudiar concienzudamente hasta en sus más pequeños pormenores, los argumentos que deben ocupar los cuatro cuadros, propondrá la que sea más conveniente, sin faltar en un ápice a la verdad histórica, y señalando con su imparcial buril a aquellos Reyes o aquellos sabios españoles que se hayan distinguido por sus acciones heroicas, por su sabiduría, o por qualquiera de las otras condiciones que contribuyen a la justa celebridad que disfrutaron en su vida.

Las doctas corporaciones, según se ha podido comprobar, apenas prestan atención a la Apoteosis de los hombres célebres; la de Bellas Artes no llega a mencionar este cuadro de forma individualizada y la de la Historia, cuando lo hace, obvia por completo las figuras que acompañan a Isabel II, llegando a considerar la obra como la apoteosis de la propia Reina. Por lo tanto, queda claro que las modificaciones que se producen entre la concepción original y la factura final del medallón no son obra de ninguna de las dos reales academias.

\section{La aprobación del proyecto: la intervención del Ministerio de Fomento y el Consejo de Ministros}

Hasta el momento nadie ha propuesto modificación alguna sobre la Apoteosis. De inmediato se plantea, pues, que fue el Poder Ejecutivo el que finalmente intervino en esta cuestión.

Se esperaría poder constatar documentalmente este extremo a partir del Archivo que fue del Consejo de Ministros ${ }^{16}$ y, sin embargo, en el actual Archivo Central del Ministerio de la Presi-

${ }^{15}$ A pesar de lo argumentado por la Real Academia, Díez García subraya, partiendo de la consideración formulada por el propio Ribera, que no es, contra lo que era habitual en este tipo de representaciones, la representación de Isabel II una alegoría de la Monarquía, sino que más bien simboliza a España misma, hecho este que "encierra en su significación un matiz novedoso y hasta ahora no suficientemente advertido en el uso simbólico de la imagen de la Reina" (Díez García, 2010: 50).

${ }^{16}$ El papel del Consejo de Ministros durante el reinado de Isabel II ha sido objeto de estudio por parte, entre otros, de Joaquín Tomás Villarroya. El autor advierte, antes de entrar en el fondo de la cuestión, que el análisis de la Presidencia del Gobierno y del Consejo de Ministros durante el reinado isabelino presenta varias dificultades, entre las que 
dencia no se conservan las Actas del Consejo correspondientes al periodo 1844-1854. En la "Introducción" a las Actas de 1833-1874, Javier García Fernández, entonces Secretario General Técnico del Ministerio de la Presidencia, señala con pesar que no ha sido posible localizar las que afectan a este período y algunas más, ni en España ni fuera. Desconoce si se perdieron o se destruyeron deliberadamente, pues de lo que sí está seguro es de que existieron ${ }^{17}$.

Parece cierto, a la vista de los expedientes consultados hasta el momento, que el ministro Seijas tuvo una influencia decisiva en la aprobación del proyecto, pues él impulsa con cierta premura, como por otra parte era el deseo de la Comisión de Obras del Congreso, que se emitan los informes de las academias al respecto de la propuesta de Ribera, y mantiene correspondencia con el pintor.

Manuel Seijas es una interesante figura de nuestro siglo XIX, con una intensa trayectoria tanto en el ámbito político como académico ${ }^{18}$. Durante su mandato al frente del departamento de Comercio, Instrucción y Obras Públicas se inauguran el nuevo Palacio del Congreso de los Diputados y también el Teatro Real, y es que el reinado de Isabel II conoció una considerable efervescencia de la construcción de edificios públicos, pues "la opinión general era favorable a la ejecución de las mismas a pesar de la escasez de recursos económicos"19.

En este sentido puede entenderse que el departamento dirigido por él impulsó y apoyó las obras públicas, como se colige a través de la documentación contemporánea. En un legajo del Archivo General de la Administración que reúne documentos relativos a edificios costeados por el Estado se localiza un expediente relativo al Palacio del Congreso de los Diputados ${ }^{20}$. En él se encuentran los dos originales de los informes emitidos por las reales academias, la copia de la Memoria que presenta Ribera y que se somete a examen, minutas de los documentos que obran en los expedientes de los otros archivos consultados y el extracto redactado por el ministerio, así como diversas comunicaciones mantenidas entre la Comisión para la Obra del nuevo Palacio, el Ministerio de Hacienda y el de Comercio, Instrucción y Obras Públicas.

Varios de ellos contribuyen a poner de relieve el papel de Seijas. Quizá el más interesante, por condensar todos los avatares sufridos por el proyecto de Ribera, es el extracto del ministerio. Comienza éste por recoger la petición de la Comisión de Obras para que se dictamine sobre el asunto. Se añade una nota en la que se indica que se consulte a las Reales Academias, si bien se advierte que no se busca, como sucedió con el frontón, convocar un certamen, pues ya se ha escogido al pintor, quien "goza ya de una reputación justamente conseguida", y en este aspecto no encuentra el negociado razón tampoco para que no se apruebe esto. Finalmente se indica "S. M. resolverá". Sigue después con un breve resumen de lo dictaminado por la Real Academia de Bellas Artes, y se hace constar que "En vista de este informe no ofrece ya inconveniente alguno la aprobación del proyecto", aunque en nota al margen se indica que se remita con urgencia a la Real Academia de la Historia, lo que induce a pensar que el primer

\footnotetext{
cabe destacar la falta de normativa reguladora, la "carencia casi total o la sumariedad de las Actas del Consejo durante el reinado" y, especialmente, "los condicionamientos irregulares que frecuentemente determinaron la designación, la política y la caída de los ministerios y sus respectivos presidentes" (Tomás Villarroya, 1992: 70). Para conocer la composición del Gabinete de señores Ministros que se ocupó de revisar y aprobar el proyecto de Ribera véase la base de datos Diccionario biográfico de los ministros españoles en la Edad Contemporánea (1808-2000), elaborada sobre la publicación de José Ramón y Mikel Urquijo Goitia, disponible en <http://humanidades.cchs.csic.es/ih/paginas/jrug/ diccionario/index_dic.htm>, [consultado: 23-01-2018].

17 Actas, 1995: XV.

${ }_{18} \mathrm{Su}$ labor fue especialmente relevante en el ámbito de la codificación, pero ejerció también como abogado, fiscal y magistrado. Llegó a ser Presidente del Congreso de los Diputados y ocupó escaño varias legislaturas, fue además senador y accedió también a la presidencia de la cámara alta; fue ministro en varias ocasiones de carteras distintas y alcanzó la presidencia del Consejo de Estado en 1858. En el plano académico, alcanzó en dos ocasiones la presidencia de la Real Academia de Jurisprudencia y Legislación. Ingresó además en 1852 en la Real Academia de la Historia y formó también parte de la Real Academia de las Ciencias Morales y Políticas.

19 Fernández, 2007: 197.

20 AGA, IDD (05)014.002, caja 31/08274, exp. 9005-14: "Expediente relativo a las obras de construcción del Palacio del Congreso (1843-1864)".
} 
informe bastaba ya para que el proyecto siguiera su curso. Sigue el extracto con lo indicado por esta corporación, y a pesar de ello, al margen y con fecha de 27 de marzo, se recoge que el Consejo de Ministros ha acordado aprobar el pensamiento del pintor y autorizar su ejecución con las observaciones y rectificaciones hechas por él, enterado ya de lo objetado por la Real Academia de la Historia. A continuación se recogen los personajes de cada uno de los cuadros y, en lo que respecta al quinto cuadro, aparecen enumerados todos los célebres que ornarán el medallón, citándose, por vez primera, a Cervantes, indicando de forma definitiva las elecciones, como sucede con la escultura y la arquitectura, pero sin hacer mención a Salinas. Y esto se data el 29 de marzo de 1850.

Antes de que se cierre definitivamente el extracto tendría lugar un intercambio epistolar entre el ministro y Carlos Luis de Ribera; el primero le escribiría para comunicarle lo dictaminado por la Academia de la Historia y el segundo le contesta con una carta con fecha de 26 de marzo de 1850 en la que indica que "le remito adjunto, después de bien meditado, el proyecto con las modificaciones, y ruego a V. E. la brevedad de su despacho". La carta remitida por el ministro se antoja extremadamente interesante, pues aunque se puede adivinar que hace saber a Ribera que son precisos algunos cambios, conocer los términos en los que lo hizo y si justifica de algún modo el cambio de personajes a incluir en el medallón sería muy clarificador.

Así prevenido por el ministro de lo que sugiere la corporación, rectifica el pintor su proyecto, pero levemente. Justifica esto diciendo que:

Este pensamiento [su proyecto para la bóveda] no sólo fue bien acogido por la prensa pública, puesto que no hubo periódico en Madrid que dejara de insertarlo en sus columnas, sin censura alguna, sino que mereció también el honor de ser elogiado por la prensa inglesa y francesa, en el Morning Chronicle y la Presse, tanto por su originalidad, como porque haría notable la Cámara de los Diputados españoles. La Real Academia de Nobles Artes de San Fernando, corporación ilustre y competente en el asunto, también lo aprobó por unanimidad; pero la de la Historia ha discordado respecto á algunos personages [refiriéndose a los cuadros laterales].

También en el resumen de personajes que acompaña a la exposición motivada que hace el pintor se cierra la nómina definitiva de personajes ilustres llamados a ornar el quinto cuadro, excepción hecha de Salinas.

El documento dirigido por Seijas a su vez a la Comisión de Obras del Congreso confirma este extremo, al tiempo que se comunica por este medio del visto bueno a esta modificación del Consejo de Ministros y la Reina, quienes se han servido aprobarlo; y de Real Orden lo comunica él el día de la fecha, 29 de marzo de 1850.

Así, pues, las cartas que intercambiaron Seijas y Ribera, de las que no se conservan aquí las dirigidas por el Ministro, y el extracto del asunto elaborado por el ministerio demuestran que Seijas siguió de cerca el periplo y que él fue quien transmitió a Ribera, aunque de forma sucinta o suavizada, la opinión de la Real Academia de la Historia, pues no comparte, parece, la idea de la corporación de dejar en blanco los cuadros, sino que más bien sugiere al artista que enmiende su obra pero siguiendo adelante con la idea inicial y escoge, por último, los personajes que habrán de ocupar el medallón central.

\section{La Memoria de Narciso Pascual y Colomer: la foto fija del medallón}

La ejecución del proyecto de Ribera para la pintura del techo del salón de sesiones se lleva a cabo entre 1850 y 1852, pues a pesar de que el palacio se inaugura el 31 de octubre de 1850, la obra aún no está terminada y son varios los remates que quedan pendientes.

La Memoria que publica el arquitecto del palacio, Narciso Pascual y Colomer, en 1856 sirve para analizar, como si de una foto fija se tratara, el estado del nuevo edificio en torno a la fecha de su publicación, y en ella se presta gran atención al análisis y descripción del salón de sesiones. En ella se alude al medallón central como Apoteosis de los Españoles célebres, siendo, pues, este 
el nombre que definitivamente se adjudicó al que hasta el momento se aludía en la mayor parte de las ocasiones como "quinto cuadro".

El iter que siguió la propuesta inicial de Ribera hasta su aprobación definitiva someramente recogido por el arquitecto, quien señala que:

Sometido á la aprobación del Gobierno de S. M. por dicha Comision, y examinado de orden de la Reina Nuestra Señora por las Reales Academias de San Fernando y de la Historia, obtuvo completa sancion de estos respetables cuerpos, limitándose el último á indicar leves modificaciones, que en nada alteraban el pensamiento del estudioso artista ${ }^{21}$.

Sigue Pascual y Colomer con la obra de Ribera y, tras describir con profusión los cuadros relativos a la historia de la legislación, procede a detallar el medallón central:

El plano central del paflon, sitio de preferencia, está decorado con una gran medalla circular, en cuyo centro, sentada en un trono al que dan subida tres gradas, y con el pie izquierdo puesto en un escabel, aparece S. M. la Reina Doña Isabel II como alegoría de España [...]. Una matrona, vestida de blanco en testimonio de pureza, simboliza la Nación [...]. Dos Famas, la de la fuerza y la del saber, coronan á la augusta Señora que simboliza la España, y en rededor suyo se ven representadas por medio de varones ilustres, las ciencias que física y moralmente han dado á nuestra Nación engrandecimiento y renombre. El Cid Ruy Diaz de Vivar, que pisa con generoso y marcial conteniente las gradas del trono como su más bizarro defensor; Cristóbal Colon, cuya mano derecha sostiene un globo del que muestra el hemisferio occidental; D. Diego de Saavedra Fajardo, y los jurisconsultos conde de Campomanes y D. Melchor Gaspar de Jovellanos, significando el arte militar, la naútica, la diplomacia, la jurisprudencia y la economía, ocupan digno puesto á la derecha del Trono, y á su izquierda, no menos honradas que dichas ciencias, están la literatura y las Nobles artes, arquitectura, pintura, escultura y música, espresadas por el P. Juan de Mariana, Luis Vives, Miguel de Cervantes, Lope de Vega, D. Diego Velazquez de Silva, Juan de Herrera, Alonso Berruguete y el ciego Francisco Salinas ${ }^{22}$.

Esta que se describe en la Memoria es la apariencia final de la Apoteosis. No hay más cambios sobre lo aprobado por el Gobierno que la inclusión del músico Salinas. Parece, por la disposición de la figura en la composición (apenas se ve su cabeza con los ojos velados para representar su ceguera y una mano que sostiene una partitura inmediatamente detrás de Cervantes) que fuera una adición un tanto improvisada que se hiciera en atención a que no había representante alguno de la música (fig. 2).

La composición final de la obra revela un cierto desequilibrio entre uno y otro de los lados en cuanto al número de figuras. Asimismo, en los casos en lo que se presentaban elecciones y se ha optado por la presencia de dos figuras, como sucede con Campomanes y Jovellanos, pareciera que ambas cabezas compartieran parte del cuerpo (fig. 3).

\section{A modo de conclusión: la Apoteosis en la construcción de la cultura nacional a mediados del siglo XIX}

El Palacio de las Cortes es una obra meditada con sumo cuidado hasta el último de sus detalles con una clara y evidente vocación de trascender o, como bien señala Díez García, buscando "un poso de intemporalidad y permanencia, sólido, contundente y de un inequívoco carácter representativo" 23 . Por este motivo el pintor Carlos Luis de Ribera expone con profusión el programa iconográfico que sustenta la decoración del techo del salón de sesiones, y es enormemen-

\footnotetext{
21 Pascual y Colomer, 1856: 39.

22 Pascual y Colomer, 1856: 47-48.

23 Díez, 2010: 48.
} 


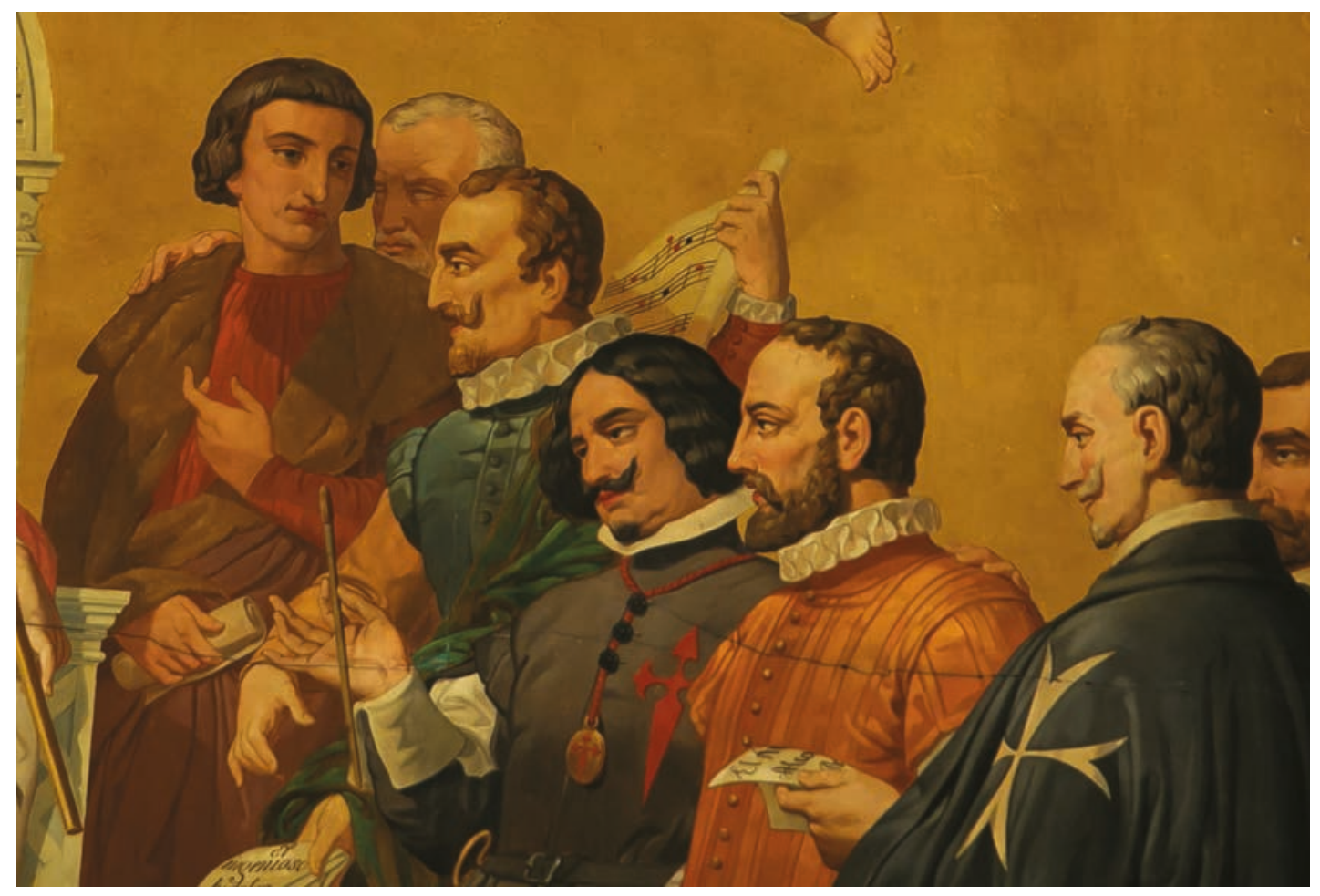

Fig. 2. Detalle del medallón de la bóveda con algunos de los personajes que se encuentran a la izquierda de Isabel II.

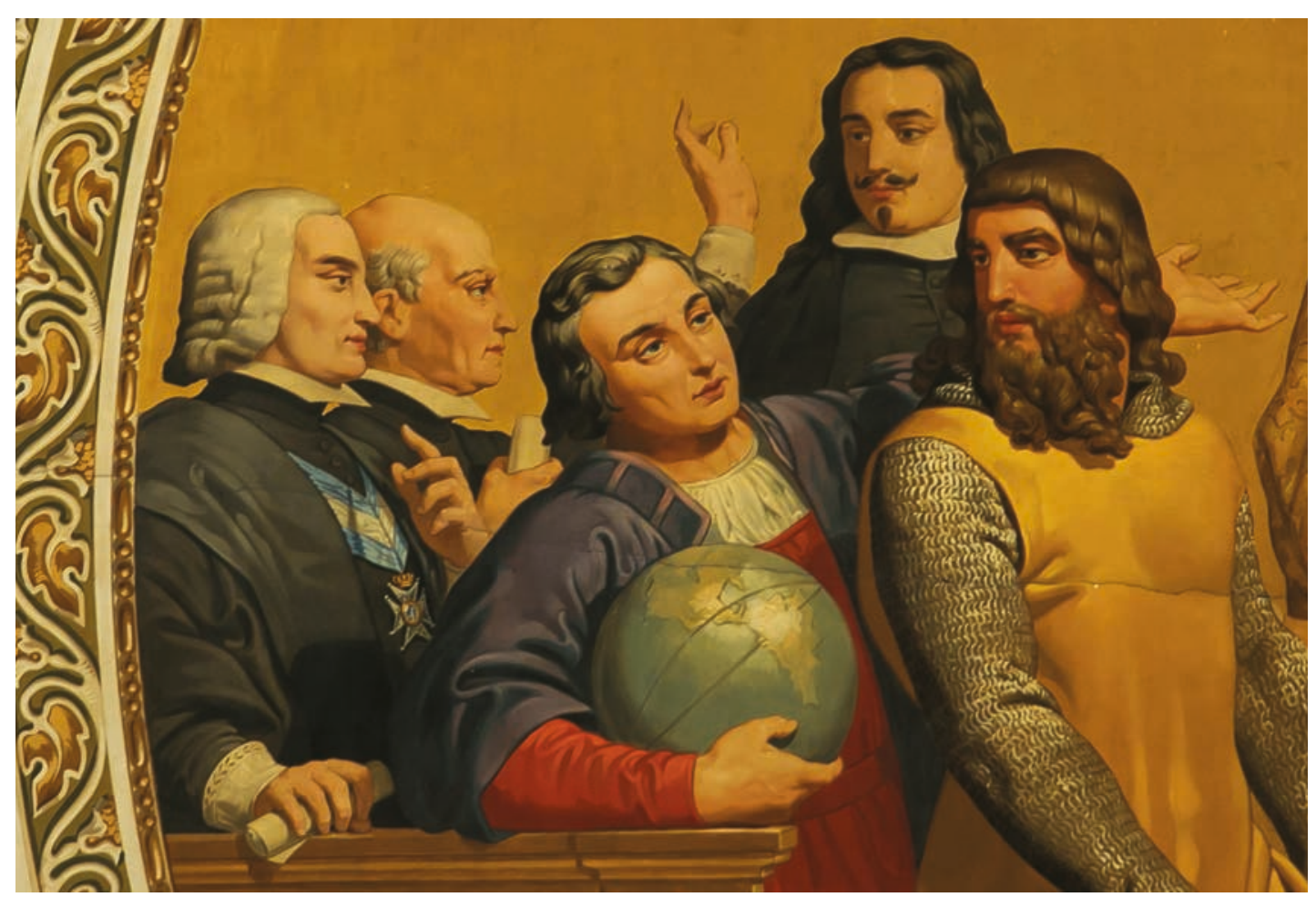

Fig. 3. Detalle del medallón de la bóveda con los ilustres que se encuentran a la derecha de Isabel II. 
te significativo que el artista dedique mucha más extensión a la descripción y justificación de las pinturas que a la técnica escogida y el modo en el que se va a llevar a cabo esta decoración.

En lo que respecta al medallón central, fue recibido por sus contemporáneos esencialmente como representación de la Reina, a pesar de lo que dicen los documentos y de que, como sostiene Carlos Reyero, "la imagen del Congreso de los Diputados es independiente de la institución monárquica" ${ }^{24}$. No es, desde luego y según se desprende del pensamiento de Ribera, la Reina la única protagonista, aunque ocupe la posición central del cuadro, pues lo hace como encarnación de España, sino que lo son también los ilustres que la acompañan, dado que encarnan lo mejor del genio patrio en todos los ámbitos. Solo de la reunión de todos ellos puede surgir la inspiración del trabajo parlamentario que pretende el pintor.

Es también posible concluir que la Apoteosis de Carlos Luis de Ribera sufrió diversas modificaciones entre su planteamiento inicial y su ejecución final, tal y como indica Pilar de Miguel al describir, en la identificación del boceto de la misma, que guarda algunas diferencias con el medallón "en relación con el número y disposición de los personajes representados en torno a Isabel II" 25 y como demuestran los documentos examinados. Asimismo, estas alteraciones ofrecen valiosa información sobre el modo en el que los poderes públicos, y de forma destacada el poder ejecutivo a través de Manuel Seijas, intervienen.

Los documentos examinados, especialmente los conservados en el Archivo General de la Administración, revelan el protagonismo del ministro Seijas en la aprobación definitiva del proyecto de Ribera y su participación en las decisiones relativas a su ejecución final, pues él es quien matiza, y hasta cierto punto ignora, el criterio expresado por la Real Academia de la Historia y, sobre todo, quien da el visto bueno final, garantizando asimismo que la obra, a pesar de su complejidad y extensión, se ejecute en el plazo para ello previsto.

Por otra parte, el siglo XIX bebe del imaginario cultural ilustrado, y por tal motivo sitúa a las personalidades inmortales de las letras y el arte junto a los sacrosantos valores del nuevo sistema político $^{26}$. Es por ello tan llamativo que Cervantes no estuviera incluido inicialmente entre los grandes hombres de la Historia de España, pues no cabe duda de que, cuando Carlos Luis de Ribera ejecuta esta obra, Cervantes es ya, indiscutiblemente, un autor fundamental que, de forma intensiva, se reivindicará en la segunda parte del siglo como uno de los personajes que están indisolublemente unido a la identidad nacional. José Montero sintetiza, al referirse a la herencia decimonónica en la crítica cervantina del siglo XX, que en este momento y a pesar de que el redescubrimiento y valoración de Cervantes es fruto del siglo XVIII, la centuria siguiente aporta una nueva lectura de su obra, esta vez como obra "seria", en la que podían encontrarse sabios consejos para conducirse en la vida y cuyo creador se identifica de algún modo con un rasgo nacional, primando así una visión nacionalista del mismo cuya presencia se intensificará en las Exposiciones Nacionales de Bellas Artes, que actúan como "escaparates por excelencia del arte oficial"27.

En este sentido, mediando el siglo XIX es Cervantes ya una figura central de la cultura española, uno de los símbolos de la nación; más aun teniendo en cuenta que una de las primeras representaciones públicas del escritor es la estatua que Antonio Solá realiza para la plaza de Santa Catalina de Madrid, hoy plaza de las Cortes, en 1835, y que cuando se escoge el edificio del convento del Espíritu Santo para albergar el nuevo Palacio de las Cortes, quedan ambos indisolublemente unidos en la estampa de este rincón madrileño ${ }^{28}$. Por esto, entre otras cuestiones, es

${ }^{24}$ Reyero, 2015: 93.

25 Según de Miguel este boceto pertenece a la colección particular de Jesús López Galán y fue expuesto en una muestra monográfica dedicada a Carlos Luis de Ribera en el Museo Romántico en 1955. Se trata, según su descripción, de un óleo sobre cartón, de $0.28 \mathrm{~m}$ de diámetro y está fechado hacia 1850 (de Miguel, 1983: 101). Asimismo, el diario $A B C$ de 7 de julio de 1955 da noticia de esta misma muestra indicando que "se exponen aquí [en el Museo Romántico], también, dibujos y bocetos de su obra de decorador para el Congreso de los Diputados" ( $A B C$, Madrid, 07/07/1955, p. 39).

${ }^{26}$ Reyero, 2016: 161.

27 Montero, 2001: 196-198.

28 Reyero, 2016: 154-155. 
tan curiosa la ausencia inicial del escritor y tan significativo que sea el Gobierno, a través del ministro Seijas, quien repare en ello, acentuando el carácter político y la lectura simbólica del medallón del techo, que viene a condensar el peso de la herencia cultural en la construcción del nuevo tiempo político.

Por otra parte, la incorporación de la música y su encarnación en Francisco Salinas sigue siendo aún, al menos a la vista de la documentación examinada, un pequeño misterio, pues nada se dice sobre él y sin embargo está presente entre los ilustres de este privilegiado parnaso. Queda pendiente averiguar cómo se llevó a cabo la adición tardía de la música y quién propuso a Salinas como su representante. Lo que queda patente, a la vista de la documentación examinada, es que Salinas es incorporado extemporáneamente a la aprobación final del proyecto y que ninguna de las academias consultadas, ni el Gobierno a través de su Ministro de Fomento ni la Comisión de Obras hace alusión alguna a la falta de representación de la música y, sin embargo, hoy el músico se encuentra entre los más ilustres representantes de la gloria nacional.

\section{BIBLIOGRAFÍA}

Actas del Consejo de Ministros. Isabel II, Tomo IX (1833-1839). (1995): Madrid: Ministerio de la Presidencia.

Bonet-Correa, Antonio/ Arias de Cossío, Ana María (1998): "Las artes plásticas". En: El Congreso de los Diputados. Madrid: Congreso de los Diputados, pp. 236-315.

De Cárdenas Piera, Emilio (1996): Propuestas, solicitudes y decretos de la Real y Distinguida Orden de Carlos III, Tomo V (Decretos R-Z). Madrid: Instituto Salazar y Castro.

De Miguel Egea, Pilar (1983): Carlos Luis de Ribera, pintor romántico madrileño. Madrid: Fundación Vega-Inclán.

Díez García, José Luis (2010): La pintura isabelina. Arte y Política. Discurso leído el 6 de junio de 2010 en el acto de su recepción por el Excmo. Sr. D. José Luis Díez García y contestación por la Excma. Sra. D. ${ }^{a}$ Carmen Iglesias. Madrid: Real Academia de la Historia.

Fernández, Nicolás Antonio (2007): Manuel de Seijas Lozano: tras las huellas de un liberal olvidado. Madrid: Colegio de Registradores de la Propiedad y Mercantiles de España.

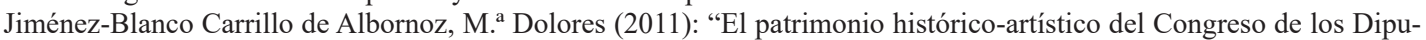
tados antes de 1978". En: VV.AA.: El patrimonio histórico-artístico del Congreso de los Diputados. Madrid: Congreso de los Diputados, pp. 15-161.

Montero Reguera, José (2001): “La crítica sobre el Quijote en la primera mitad del siglo XX”. En: Bernat Vistarini, Antonio, ed., Volver a Cervantes. Actas del IV Congreso Internacional de la Asociación de Cervantistas. Palma: Universitat de Illes Balears, pp. 195-236.

Navarro, Carlos G. (2015): "Del reinado de Isabel II a la crisis del fin de siglo: panorama de la pintura decorativa madrileña decimonónica". En: Manzarbeitia Valle, Santiago, coord., Pintura mural en la Comunidad de Madrid. Madrid: Comunidad de Madrid. Dirección General de Patrimonio Histórico, pp. 416-497.

Navascués Palacio, Pedro (2007): "El Congreso de los Diputados". En: VV.AA., Narciso Pascual y Colomer (1808-1870). Arquitecto del Madrid isabelino. Madrid: Ayuntamiento de Madrid, pp. 61-99.

Navascués Palacio, Pedro (1998): "El palacio". En: El Congreso de los Diputados. Madrid: Congreso de los Diputados, pp. 164-231.

Pascual y Colomer, Narciso (1856): "Introducción”. En: Memoria histórico-descriptiva del nuevo Palacio del Congreso de los Diputados publicada por la Comisión de Gobierno Interior del mismo. Madrid: Aguado.

Reyero, Carlos (2016): "La fortuna visual de Cervantes". En: Miguel de Cervantes: de la vida al mito (1616-2016). Madrid: Biblioteca Nacional de España y Acción Cultural Española, pp. 139-165.

Reyero, Carlos (2015): Monarquía y Romanticismo. El hechizo de la imagen regia (1829-1873). Madrid: Siglo XXI.

Reyero, Carlos (2010): Alegoría, nación y libertad. El olimpo constitucional de 1812. Madrid: Siglo XXI.

Pérez-Serrano Jaúregui, Nicolás (2009): En un lugar de las Cortes... El Congreso: trashumancia, nomadismo y destierro hasta lograr una sede fija en Madrid. Madrid: Congreso de los Diputados.

Portela Sandoval, Francisco José (2015): "Nuevas aportaciones a la biografía de varios artistas del siglo XIX". En: Anales de Historia del Arte, 15, pp. 247-268.

Salvá, Amalia (1997): Colecciones artísticas del Congreso de los Diputados. Madrid: Congreso de los Diputados.

Tomás Villarroya, Joaquín (1992): "El Gobierno durante el reinado de Isabel II”. En: VV.AA., 1812-1992. El arte de gobernar. Historia del Consejo de Ministros y de la Presidencia del Gobierno. Edición preparada por el Ministerio de Relaciones con las Cortes y de la Secretaría de Gobierno. Salamanca: Tecnos, pp. 69-100.

Fecha de recepción: 21-II-2018

Fecha de aceptación: 03-VII-2018 